\title{
Verificação da adaptabilidade e estabilidade de populações de cenoura pelos métodos AMMI, GGE biplot e REML/BLUP
}

\author{
Giovani Olegario da Silva $\left({ }^{1 *}\right)$; Agnaldo Donizete Ferreira de Carvalho $\left({ }^{2}\right)$; Jairo Vidal Vieira $\left({ }^{2}\right)$; \\ Giovani Benin ( $\left.{ }^{3}\right)$ \\ (') Embrapa SNT, Caixa Postal 317, 89460-000 Canoinhas (SC). \\ (2) Embrapa Hortaliças, Caixa Postal 218, 70359-970 Brasília (DF). \\ (3) Universidade Tecnológica Federal do Paraná, Via do conhecimento, Km 01, 85501-970 Pato Branco (PR) \\ (*) Autor correspondente: giovaniolegario@gmail.com
}

Recebido: 16/set./2010; Aceito: 2/mar./2011

\begin{abstract}
Resumo
O objetivo desse estudo foi verificar a adaptabilidade e estabilidade de populações de cenoura diante de ambientes com cultivo orgânico e convencional e realizar a comparação entre as metodologias estatísticas utilizadas. O trabalho foi desenvolvido em 2007 e 2008, em cinco locais. Em São Gotardo (MG); Irecê (BA) e Gama (DF) foi realizado cultivo convencional e em PAD (DF) (Programa de Assentamento Dirigido do Distrito Federal) e Gama (DF) foi utilizado o sistema de cultivo orgânico. O delineamento experimental utilizado foi o de blocos ao acaso com três repetições e parcelas de $1 \mathrm{~m}^{2}$. Foram avaliadas sete populações de cenoura do grupo Brasilia: 0912545, 0912532, 0912520, BRS Planalto, Esplanada, Brasília e Alvorada. Aos cem dias após a semeadura, foi determinada em cada parcela, em gramas, a massa das raízes com padrão comercial. Para a avaliação da adaptabilidade e estabilidade foram aplicados os métodos AMMI, GGE Biplot e REML/BLUP. As análises AMMI e GGE Biplot foram bastante semelhantes na verificação da adaptabilidade e estabilidade das populações de cenoura, e GGE Biplot agrupou de maneira mais clara os ambientes mais favoráveis e desfavoráveis. A análise REML/BLUP se destacou das demais e apesar de não informar sobre o agrupamento de locais mais semelhantes, apresenta os resultados em função de valores genotípicos levando em consideração os parâmetros de adaptabilidade e estabilidade. As populações com melhor adaptabilidade e estabilidade foram 0912532, BRS Planalto e 0912520.
\end{abstract}

Palavras-chave: Daucus carota L., interação populações x ambientes, análise multivariada, modelos mistos.

\section{Verification of the adaptability and stability of carrot populations by AMMI, GGE Biplot and REML/BLUP methods}

\begin{abstract}
The aim of this study was to verify the adaptability and stability of carrot populations for organic and conventional production systems and to draw a comparison among the used statistical methodologies. The study was carried out during 2007 and 2008, at five sites: conventional cultivation was performed in Sao Gotardo (MG), Irece (BA) and Gama (DF); and organic production system was performed in PAD-DF and Gama (DF). The experiment was arranged in complete randomized block design with tree replications and plots of $1 \mathrm{~m}^{2}$. Seven carrot populations from the Brasilia group were evaluated: 0912545, 0912532, 0912520, BRS Planalto, Esplanada, Brasilia and Alvorada. One-hundred days after sowing, the root mass with commercial value was evaluated in each plot. The methodologies AMMI, GGE Biplot and REML/BLUP were applied for evaluating the adaptability and stability. AMMI and GGE Biplot obtained very similar results regarding adaptability and stability of carrot populations; however GGE Biplot grouped the more favorable and unfavorable environments more clearly. The REML/BLUP analysis did not group of the most similar areas; however, it presented the results as function of genotypic values taking into account the parameters of adaptability and stability. The populations that presented the best adaptability and stability were 0912532, BRS Planalto and 0912520.
\end{abstract}

Key words: Daucus carota L., populations x environment interaction, multivariate analysis, mixed models. 


\section{INTRODUÇÃO}

As plantas têm o desenvolvimento afetado pelos efeitos de ambiente $(A)$, genótipo $(G)$ e da interação entre ambos $(\mathrm{GxA})$, sendo o último efeito o que promove significativas diferenças no desempenho das cultivares quando estas são cultivadas em diferentes locais (MoHAmmadi et al., 2007).

Nesse contexto, algumas populações de plantas possuem adaptação ampla enquanto outras são restritas a determinadas condiçôes ambientais de cultivo. A presença da GxA interfere de forma intensa nos programas de melhoramento, pois em uma situação ideal as cultivares deveriam possuir adaptabilidade a vários ambientes e terem boa estabilidade, porém o fator interaçấo faz com que, na maioria das vezes, as cultivares sejam indicadas a ambientes específicos, por possuírem maior adaptabilidade nessas condiçôes ambientais (CAMPBELl e Jones, 2005). O termo adaptabilidade refere-se à capacidade dos genótipos responderem de forma positiva ao estímulo do ambiente, enquanto a estabilidade refere-se à capacidade dos genótipos desempenharem um comportamento previsível em função do estímulo do ambiente (Cruz e Regazzi, 2001).

Alguns métodos têm sido propostos para avaliar a adaptabilidade e estabilidade produtiva quando ocorre a interação GxA, sendo exemplos as metodologias de Wricke, Eberhart e Russell, de Lin e Binns (Cruz e Regazzi, 2001). Entretanto, a maioria desses métodos não é capaz de explicar adequadamente a resposta dos genótipos quando submetidos a cultivo em diferentes localidades (Osmanzai e Sharma, 2008; Namorato et al., 2009; Zobel et al., 1988; Duarte e Zimmerman, 1994).

Nesse contexto, há metodologias recentes e que explicam adequadamente os efeitos principais (genótipo e ambiente) e a sua interação, podendo-se destacar as análises AMMI, SREG com representação gráfica conhecida como GGE Biplot e REML/BLUP.

A análise AMMI é uma combinação de métodos univariados (análise de variância) com métodos multivariados (análise de componentes principais e decomposição de valores singulares). Esta combina em um único modelo, componentes aditivos para os efeitos principais de genótipos e de ambientes, e componentes multiplicativos para os efeitos da interação (ZoBel et al., 1988).

Segundo Yan et al. (2000), o método GGE Biplot é superior ao AMMI, pois sempre resulta no melhor modelo da análise AMMI, com a diferença de que os efeitos principais dos genótipos sáo considerados junto com o efeito da interação genótipo x ambiente, que no AMMI são estimados como efeitos aditivos (YAN et al., 2000).

A análise REML/BLUP baseia-se nas seguintes estimativas, quanto menor for o desvio-padráo do comportamento genotípico através dos locais, maior será a média harmônica de seus valores genotípicos através dos locais. Assim, a seleção pelos maiores valores da média harmônica dos valores genotípicos (MHVG) implica simultaneamente seleção para produtividade e estabilidade. Em termos de adaptabilidade, refere-se ao desempenho relativo dos valores genotípicos (PRVG) através dos ambientes. Neste caso, os valores genotípicos preditos (ou os dados originais) são expressos como proporção da média geral de cada local e, posteriormente, obtém-se o valor médio dessa proporção através dos locais. A seleção simultânea por produtividade, estabilidade e adaptabilidade, no contexto dos modelos mistos, pode ser realizada pelo método da média harmônica do desempenho relativo dos valores genéticos (MHPRVG) preditos. Esse método permite selecionar simultaneamente pelos três atributos mencionados e apresenta as seguintes vantagens: (a) considera os efeitos genotípicos como aleatórios e, portanto fornece estabilidade e adaptabilidade genotípica e não fenotípica; (b) permite lidar com desbalanceamento; (c) permite lidar com delineamentos não ortogonais; (d) permite lidar com heterogeneidade de variâncias; (e) permite considerar erros correlacionados dentro de locais; (f) fornece valores genéticos já descontados (penalizados) da instabilidade; (g) pode ser aplicado com qualquer número de ambientes; (h) permite considerar a estabilidade e adaptabilidade na seleção de indivíduos dentro de progênie; (i) não depende da estimação de outros parâmetros tais quais coeficientes de regressão; (j) gera resultados na própria grandeza ou escala do caráter avaliado; (k) permite computar o ganho genético com a seleção pelos três atributos simultaneamente (RESENDE, 2002).

Há vários estudos comparando os métodos AMMI e GGE Biplot, e em alguns há evidências da superioridade da metodologia GGE Biplot e outros da AMMI (YAN et al., 2000; GAUCH, 2006; GAUCH et al., 2008; YAN et al., 2007; Asfaw et al., 2009; Namorato et al., 2009).

O método GGE Biplot é superior ao AMMI, pois sempre resulta no melhor modelo da análise AMMI (YAN et al., 2000). Entretanto, Balestre et al. (2009) comparando os métodos GGE Biplot e AMMI afirmam que o modelo GGE Biplot é superior ao AMMI apenas quando há a seleção do AMMI1, neste caso há superioridade da GGE Biplot devido à maior captação da soma de quadrados e acurácia preditiva, enquanto o AMMI2 foi superior. Segundo Carbonell et al. (2007), o método REML/ BLUP é superior à análise AMMI, pois os efeitos genéticos e da interação são tratados como fixos em AMMI, atuando apenas em nível fenotípico, enquanto REML/ BLUP atua em nível genotípico.

O objetivo deste estudo foi verificar a adaptabilidade e estabilidade de populaçóes de cenoura frente a ambientes com cultivo orgânico e convencional e realizar a comparação entre métodos estatísticos utilizados.

\section{MATERIAL E MÉTOdOS}

O presente trabalho foi desenvolvido em 2007 e 2008, em cinco locais, ou seja, em São Gotardo (MG); Irecê 
(BA) e Gama (DF) - com cultivo convencional; em Gama (DF) e PAD-DF (Programa de Assentamento Dirigido do Distrito Federal) com cultivo orgânico, para todas as populaçóes estudadas. Os experimentos foram instalados em setembro e colhidos em dezembro de cada ano.

No sistema convencional, foi feita adubação química com nitrogênio, bórax, sulfato de zinco monohidratado, $\mathrm{K}_{2} \mathrm{O}$ e $\mathrm{P}_{2} \mathrm{O}_{5}$ no plantio, e de nitrogênio em cobertura. Foi utilizado também controle químico para doenças e controle de plantas daninhas em pré-emergência. No sistema orgânico, utilizou-se composto orgânico, formulado conforme Souza e AlCÂnTara (2008) e o controle de plantas daninhas foi realizado mecanicamente.

O delineamento experimental utilizado para todos os experimentos foi o de blocos ao acaso com três repetiçôes. Foram avaliados sete populaçôes de cenoura do grupo Brasília: 0912545, 0912532, 0912520, BRS Planalto, Esplanada, Brasília e Alvorada. Todas as populaçóes são de polinizaçáo aberta e formadas pelo intercruzamento de famílias meio-irmãs. Brasília, Alvorada, Esplanada e BRS Planalto já são cultivares, enquanto as populaçôes 0912545,0912532 e 0912520 ainda estão em fase de seleção e pertencem ao grupo Brasília. Porém se diferenciam por uma série de características além do rendimento de raízes. A cultivar Brasília destaca-se pelo bom formato de raiz e resistência à queima-das-folhas e a nematóides; Alvorada possui as mesmas características de Brasília, porém com menor tamanho de raiz e maior quantidade de betacaroteno na raiz; BRS Planalto tem características semelhantes à Alvorada, porém com raízes maiores; Esplanada possui raízes longas e finas, portanto é adaptada ao processamento industrial; 0912545 é adaptada ao consumo "in natura" e com exceção de Esplanada tem raízes mais finas que as demais, além de formato de ponta mais afilado; 0912532 possui elevada porcentagem de germinação a 20 ${ }^{\circ} \mathrm{C}$; e 0912520 destaca-se pelo elevado potencial produtivo e coloração de raízes.

As parcelas constituíram-se de $1 \mathrm{~m}^{2}$, com espaçamento de $20 \mathrm{~cm}$ entre linhas e $5 \mathrm{~cm}$ entre plantas. Aos cem dias após a semeadura foi determinada em cada parcela, em gramas, a massa das raízes com padráo comercial, de acordo com o padrão proposto pela CEAGESP (1999), sendo considerado como raiz não comercial, aquelas com diâmetro inferior a $2 \mathrm{~cm}$ no terço médio superior.

Para a avaliação da adaptabilidade e estabilidade foram aplicadas as metodologias AMMI (ZoBEL et al., 1988), GGE Biplot (YAN et al., 2000) e REML/BLUP (Resende, 2002).

Para utilização do método AMMI, o modelo empregado foi:

$$
Y_{i j}=\mu+g_{i}{ }^{+} a j+\sum_{k=1}^{n} \lambda k \gamma_{i k} a j k^{+} \rho_{i j}{ }^{+} \varepsilon_{i j}
$$

Em que: $\mathrm{Y}_{\mathrm{ij}}$ é a resposta média da população $\mathrm{i}(\mathrm{i}=1$, $2, \ldots, \mathrm{G}$ populaçóes) no ambiente $\mathrm{j}(\mathrm{j}=1,2, \ldots, \mathrm{A}$ ambien- tes); $\mu$ é a média geral dos ensaios; gi é o efeito fixo da populaçáo i; aj é o efeito fixo do ambiente j; $\lambda \mathrm{k}$ é o k-ésimo valor singular (escalar) da matriz de interaçóes original (denotada por GA); rik é o elemento correspondente à i-ésima população, no k-ésimo vetor singular coluna da matriz GA; ajk é o elemento correspondente ao j-ésimo ambiente, no k-ésimo vetor singular linha da matriz GA; pij é o resíduo associado ao termo (ga)ij da interação clássica da população i com o ambiente j; $\varepsilon$ ij é o erro experimental médio.

O método GGE Biplot foi embasado no seguinte modelo:

$$
Y_{i j}-\bar{y}_{j}=y_{1} \varepsilon i 1 \rho_{j 1}{ }^{+} y_{2} \varepsilon i 2 \rho_{\mathrm{j} 2}{ }^{+} \varepsilon_{i j}
$$

Em que: Yij representa o rendimento médio da i-ésima população no j-ésimo ambiente; $\bar{y}_{j}$ é a média geral das populaçôes no ambiente j; $y_{1} \varepsilon_{i 1} \rho_{j 1}$ é o primeiro componente principal (IPCA1); $y_{2} \varepsilon_{i 2} \rho_{j 2}$ é o segundo componente principal (IPCA2); $y_{1}, y_{2}$ são os autovalores associados ao IPCA1 e IPCA2, respectivamente; $\varepsilon_{1}$ e $\varepsilon_{2}$ são os escores do primeiro e segundo componente principal, respectivamente, da i-ésima população; $\rho_{j 1}$ e $\rho_{j 2}$ são os escores do primeiro e segundo componente principal, respectivamente, para o j-ésimo ambiente; $\varepsilon_{i j}$ é o erro do modelo associado com a i-ésima população e j-ésimo ambiente (YAN e Kang, 2003).

Para a análise REML/BLUP foi utilizado o seguinte modelo estatístico para avaliação genética pelos maiores valores da média harmônica dos valores genotípicos:

$$
Y=X r+Z_{g}+W_{i}+e
$$

Em que: y é o vetor de dados, r é o vetor dos efeitos das combinaçôes repetição-local somados à média geral, $\mathrm{g}$ é o vetor dos efeitos genotípicos, i é o vetor dos efeitos da interação populaçáo x locais, sendo e o vetor de erros. As letras maiúsculas representam as matrizes de incidência para os referidos efeitos.

O aplicativo computacional SAS (1989) foi utilizado para realizar a análise de variância individual, tendo por finalidade a determinação da variância residual de cada ensaio para posterior teste de homogeneidade de variâncias, a análise de variância conjunta, e as análises GGE Biplot e AMMI e o Selegen (RESENDE, 2002) para a análise REML/BLUP.

Os cálculos foram realizados com a média dos dados de dois anos, devido à ausência de interação anos x populaçôes.

\section{RESULTADOS E DISCUSSÃO}

A análise de variância conjunta em relação à massa de raízes comerciais revelou que nos efeitos de população (P), anos (A) e locais de semeadura (L) ocorreram variaçôes significativas a $1 \%$ pelo teste $\mathrm{F}$ (Tabela 1 ). $\mathrm{O}$ coeficiente de variação foi de $13,78 \%$ conferindo boa precisão ao experimento, 
já que o caráter massa de raiz é altamente influenciado pelo ambiente (Vieira e Silva, 2008; Vieira et al., 2009), sendo este valor semelhante aos obtidos por Oliveira et al. (2005) e abaixo dos obtidos por Oliveira et al. (2008).

As interaçôes significativas (Tabela 1) indicam que nas populações avaliadas as respostas foram diferenciadas

Tabela 1. Resumo da análise de variância com a decomposição das somas de quadrados da interaçáo populações $\mathrm{x}$ ambientes para o caráter massa de raízes com padrão comercial

\begin{tabular}{lcc|}
\hline F.V. & G.L. & Quadrados Médios \\
\hline Populações (P) & 6 & $10.372 .592^{* *}$ \\
\hline Anos (A) & 1 & $430.701 .669^{* *}$ \\
\hline Locais (L) & 4 & $496.457 .715^{* *}$ \\
\hline P x A & 6 & $719.206^{\text {ns }}$ \\
\hline P x L & 24 & $1.560 .784^{* *}$ \\
\hline A x L & 4 & $166.166 .854^{* *}$ \\
\hline P x A x L & 24 & $1.035 .278^{\text {ns }}$ \\
\hline CV (\%) & & 13,78 \\
\hline **: Significativo a 1\%, pelo Teste F; ns: Não significativo. & \\
\end{tabular}

quando submetidas aos diferentes locais de semeadura, notando-se que ocorreu alteraçáo no posicionamento das populaçôes ou mudanças na magnitude das diferenças entre populaçóes e os locais de semeadura. A interação população $\mathrm{x}$ ano de cultivo não foi significativa, indicando comportamento semelhante das populaçôes nos dois anos avaliados, assim, os cálculos foram realizados com a média dos dois anos.

Para as porcentagens de explicaçáo dos eixos do modelo AMMI e GGE Biplot, observa-se que os dois primeiros componentes (IPCA 1 e IPCA 2) explicam praticamente $90 \%$ da variação (Tabela 2). Sabe-se que nos primeiros eixos há maior captação da porcentagem de padrão, com diminuição nos eixos subsequentes. Deste modo, à medida que se eleva o número de eixos selecionados, aumenta-se a porcentagem de "ruído", reduzindo o poder de predição da análise (Oliveira et al., 2003). Assim, a interpretação gráfica da adaptabilidade foi feita considerando apenas o biplot com o modelo AMMI2 (Figura 1).

A interpretação da estabilidade pelo modelo AMMI foi realizada a partir da distância dos pontos representativos

Tabela 2. Proporção da $S_{\text {gxe }}$ da interação para cada eixo principal da análise AMMI e GGE Biplot

\begin{tabular}{lcccc} 
Componente & \multicolumn{2}{c}{ AMMI } & \multicolumn{2}{c}{ GGE Biplot } \\
Principal & Explicação & Explicação acumulada & Explicação & Explicação Acumulada \\
\cline { 2 - 5 } & & \multicolumn{2}{c}{ porcentagem } \\
IPCA1 & 58,72 & 58,72 & 67,39 & 67,39 \\
\hline IPCA2 & 30,50 & 89,22 & 21,65 & 89,05 \\
\hline IPCA3 & 10,30 & 99,52 & 8,32 & 97,37 \\
\hline IPCA4 & 0,48 & 100,00 & 2,63 & 100,00
\end{tabular}

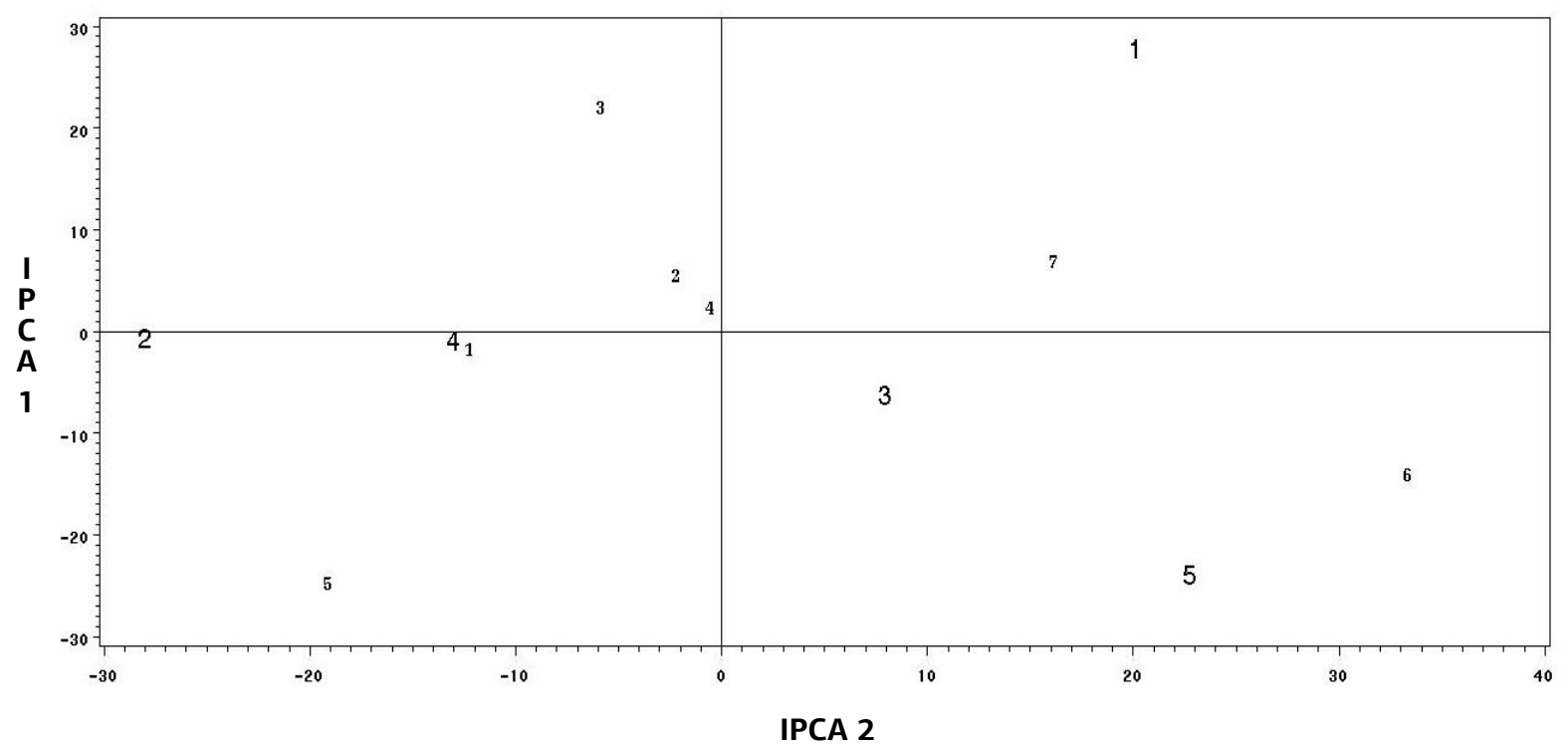

Figura 1. Plotagem dos "escores" dos componentes principais, quanto à indicaçấo locais de semeadura, segundo o modelo AMMI para o caráter massa de raiz (g) m², para sete populaçóes de cenoura cultivadas em cinco locais, nos anos agrícolas de 2007/2008 e 2008/2009. Obs.: Os números com tamanho de fonte maior representam os locais: 1: Sáo Gotardo (MG), 2: PAD (DF), 3: Gama (DF) Orgânico, 4: Gama-DF e 5: Irecê (BA). Os números com tamanho de fonte menor representam as populaçóes: 1: 0912545, 2: 0912532, 3: 0912520, 4: BRS Planalto, 5: Esplanada, 6: Brasília e 7: Alvorada. 
das populaçóes e ambientes ao escore zero. Assim, os pontos que pouco contribuem para a interaçáo representam menor distância, indicando maior estabilidade. A adaptabilidade das populaçóes em cada local de cultivo é interpretada observando-se os sinais dos escores para populaçóes e ambientes, visto que populaçóes e locais com escores de mesmo sinal interagem positivamente (DuARTE e VencovsKY, 1999), indicando em qual local a população deve ser preferencialmente cultivada.

De acordo com a análise AMMI, a cultivar Alvora$\mathrm{da}$, que se caracteriza pelo reduzido tamanho de raiz e a alta concentração de beta-caroteno, foi uma das menos produtivas. É mais adaptada a São Gotardo (MG), região do Brasil onde se emprega alta tecnologia e é considerado um ambiente muito favorável à produção de cenoura (Oliveira et al., 2005); portanto, possui os maiores rendimentos nesse local (Tabela 3). A cultivar Brasília, que originou todas as demais populaçóes deste estudo, é mais adaptada a Irecê, BA, que é o principal local de produção desta cultivar no Brasil. Estudando a adaptabilidade e estabilidade das cultivares Brasília e Alvorada em São Paulo, Minas Gerais e Paraná, Oliveira et al. (2005) verificaram que respondem bem a ambientes favoráveis e se destacaram pela tolerância à queima-das-folhas. $\mathrm{O}$ mesmo foi verificado por Oliveira et al. (2008), que avaliaram Brasília e Alvorada em várias épocas e espaçamentos de semeadura em São José do Rio Pardo (SP) (Figura 1).

A população 0912545 foi considerada estável, porém com adaptação específica a Gama (DF). As populaçóes 0912532, 0912520 e a cultivar BRS Planalto foram mais adaptadas a Gama, sob cultivo orgânico e convencional, porém com ligação pouco estreita, sendo 0912520 a mais instável das três. Já Esplanada não teve desempenho relacionado a ambientes específicos e foi muito instável. Os ambientes que mais contribuíram para a interação foram São Gotardo e PAD. Os ambientes foram bastante distintos entre si em relação à interação GxA (Figura 1). As populaçôes mais produtivas foram 0912520, BRS Planalto e 0912532 . As populaçóes 0912532 e BRS Planalto tiveram alta similaridade em termos de interação e foram também as mais estáveis em todos os ambientes.
A representação GGE Biplot (Figura 2) foi semelhante à AMMI, na qual a cultivar Brasília é adaptada a Irecê. As populações 0912532, 0912520 e BRS Planalto tiveram melhor desempenho nos ambientes Gama orgânico e convencional, que foram os ambientes mais estáveis, sendo selecionadas no Distrito Federal. A população 0912545 foi adaptada ao Gama, porém não relacionada fortemente conforme demonstrado pela análise AMMI; o que parece mais correto, pois não foi neste local que esta população obteve os maiores rendimentos. De acordo com a figura 2 a cultivar Esplanada náo se adaptou especificamente a qualquer dos ambientes. As populaçóes 0912532 e BRS Planalto tiveram alta similaridade em termos de interação e foram as mais

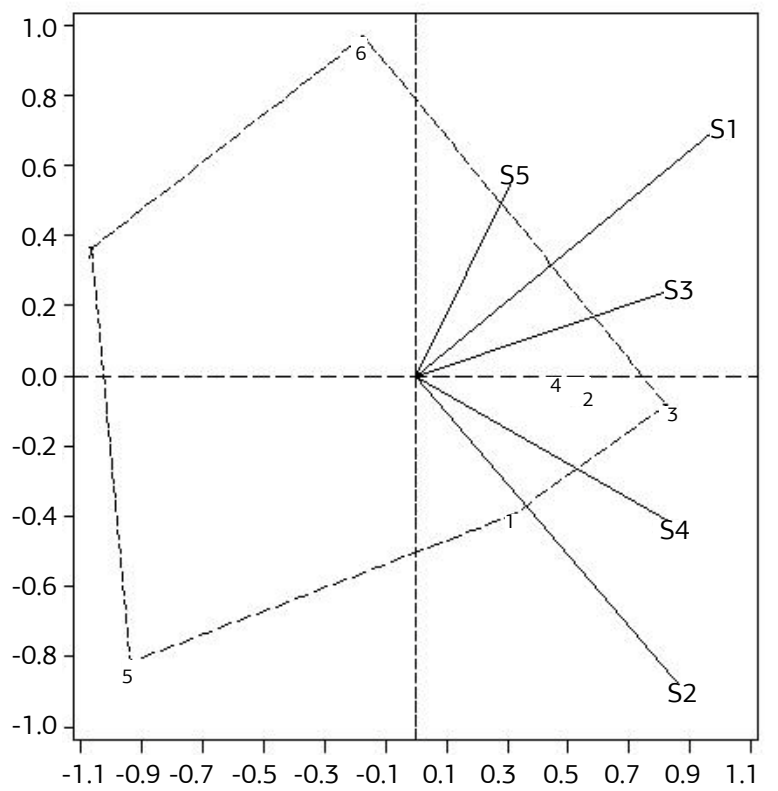

Figura 2. Plotagem dos "escores" dos componentes principais, quanto à indicação locais de semeadura, segundo o modelo GGE Biplot para o caráter massa de raiz $(\mathrm{g}) \mathrm{m}^{-2}$, para sete genótipos de cenoura cultivadas em cinco locais, nos anos agrícolas de 2007/2008 e 2008/2009. Obs.: S1: São Gotardo (MG); S2: PAD (DF); S3: Gama (DF) Orgânico; S4: Gama (DF); S5: Irecê (BA); 1: 0912545; 2: 0912532; 3: 0912520; 4: BRS Planalto; 5: Esplanada; 6: Brasília e 7: Alvorada.

Tabela 3. Médias das interações populações x ambientes para o caráter massa de raízes com padrão comercial em gramas

\begin{tabular}{|lcccccc}
\hline $\begin{array}{l}\text { População/ } \\
\text { Local }\end{array}$ & $\begin{array}{c}\text { São Gotardo } \\
\text { (MG) }\end{array}$ & PAD (DF) & $\begin{array}{c}\text { Gama (DF) } \\
\text { orgânico }\end{array}$ & Gama-(DF) & Irecê- (BA) & Médias \\
\hline 912545 & $11.005,6$ & $3.626,7$ & $6.476,7$ & $3.011,7$ & $6.609,2$ & $6.145,9$ \\
\hline 912532 & $11.547,2$ & $3.560,0$ & $6.845,0$ & $2.858,3$ & $6.755,8$ & $6.313,3$ \\
\hline 912520 & $12.211,1$ & $3.923,3$ & $6.563,0$ & $3.151,7$ & $6.658,3$ & $6.501,5$ \\
\hline BRS Planalto & $11.646,7$ & $3.601,7$ & $6.158,3$ & $3.076,7$ & $7.232,5$ & $6.343,2$ \\
\hline Esplanada & $9.345,0$ & $3.026,7$ & $5.251,7$ & $2.046,7$ & $6.220,8$ & $5.178,2$ \\
\hline Brasília & $11.234,5$ & $2.070,0$ & $6.535,0$ & $1.973,3$ & $7.607,5$ & $5.884,1$ \\
\hline Alvorada & $10.765,3$ & $1.826,7$ & $4.935,0$ & $1.440,0$ & $6.160,0$ & $5.025,4$ \\
\hline Médias & $11.107,9$ & $3.090,7$ & $6.109,2$ & $2.508,3$ & $6.749,2$ & $5.913,1$ \\
\hline
\end{tabular}


Tabela 4. Valores genotípicos das populaçôes de cenoura avaliadas para massa de raiz comercial pelo método REML/BLUP

\begin{tabular}{|c|c|c|c|c|c|c|}
\hline $\begin{array}{l}\text { População } \\
\text { /Local }\end{array}$ & $\begin{array}{l}\text { São Gotardo } \\
\text { (MG) }\end{array}$ & PAD (DF) & $\begin{array}{c}\text { Gama (DF) } \\
\text { orgânico }\end{array}$ & $\begin{array}{l}\text { Gama } \\
\text { (DF) }\end{array}$ & Irecê (BA) & Todos os locais \\
\hline 912545 & 14,1 & 404,9 & 301,7 & 384,9 & $-9,0$ & 197,8 \\
\hline 912532 & 400,8 & 419,2 & 582,3 & 346,1 & 135,9 & 340,0 \\
\hline 912520 & 869,3 & 703,6 & 471,7 & 587,7 & 138,2 & 499,9 \\
\hline BRS Planalto & 471,5 & 454,5 & 171,7 & 489,6 & 437,6 & 365,4 \\
\hline Esplanada & $-1321,4$ & $-281,3$ & $-767,1$ & $-524,7$ & $-565,6$ & $-624,4$ \\
\hline Brasília & 67,9 & $-634,5$ & 251,1 & $-337,1$ & 516,0 & $-24,6$ \\
\hline Alvorada & $-502,2$ & $-1066,3$ & $-1011,3$ & $-946,5$ & $-653,1$ & $-754,1$ \\
\hline
\end{tabular}

Tabela 5. Estabilidade de valores genotípicos (MHVG), adaptabilidade de valores genotípicos (PRVG), estabilidade e adaptabilidade de valores genotípicos (MHPRVG) para o caráter massa de raízes comerciais de populaçóes de cenoura avaliadas em cinco locais, na média das safras agrícolas de 2007/2008 e 2008/2009

\begin{tabular}{|lccc|}
\hline População & MHVG & PRVG & MHPRVG \\
\hline 0912545 & $4.873,41$ & $6.307,75$ & $6.284,92$ \\
\hline 0912532 & $4.917,31$ & $6.415,85$ & $6.402,56$ \\
\hline 0912520 & $5.169,64$ & $6.667,45$ & $6.628,37$ \\
\hline BRS Planalto & $4.998,28$ & $6.477,96$ & $6.455,99$ \\
\hline Esplanada & $3.813,37$ & $5.169,74$ & $5.155,46$ \\
\hline Brasília & $3.993,45$ & $5.657,60$ & $5.581,51$ \\
\hline Alvorada & $3.147,14$ & $4.695,12$ & $4.558,58$ \\
\hline
\end{tabular}

estáveis. Verificou-se ainda, que os ambientes que mais contribuíram para a interação foram São Gotardo (MG) e PAD-DF. No entanto, a representação GGE Biplot foi diferente da AMMI para os seguintes casos: a cultivar Alvorada não se adaptou especificamente ao ambiente São Gotardo (MG); a representação gráfica GGE Biplot proporcionou melhor agrupamento dos ambientes em relação à produtividade; São Gotardo (MG), Gama (DF) orgânico e Irecê (BA) foram os mais produtivos e semelhantes, o mesmo ocorrendo para PAD (DF) e Gama (DF), os menos produtivos (Tabela 3).

Observando-se as populaçóes com os respectivos valores genotípicos para cada local de cultivo e em conjunto para todos os locais (Tabela 4), verifica-se que as cultivares Alvorada e Esplanada tiveram os menores valores genotípicos, ou seja, o pior desempenho. Alvorada adaptou-se ao cultivo em São Gotardo (MG), porém, com baixo rendimento. Esta cultivar é conhecidamente um material diferenciado, com elevada concentraçáo de beta-caroteno, e sabe-se que quanto maior a concentração de beta-caroteno menor é o tamanho da raiz (SILVA e Vieira, 2008; Silva et al., 2009). Esplanada que se adaptou melhor ao cultivo no PAD-DF, também é uma cultivar com características específicas, de raízes longas e finas, ideais para processamento em forma de cenourete. A população 0912520 foi a mais adaptada ao conjunto de locais, principalmente para o cultivo convencional, destacando-se principalmente em Sáo Gotardo (MG); PAD (DF) e Gama (DF). Para o cultivo orgânico, destacou-se a populaçáo 0912532 em Gama (DF), e para Irecê (BA), a cv. Brasília. A população 0912545 adaptou-se melhor ao cultivo em Gama (DF) e PAD (DF), concordando com a tabela de médias (Tabela 3).

De acordo com os resultados esperados, em gramas de raiz por metro quadrado, penalizando ou capitalizando as populaçóes em função do seu desempenho, em relação à estabilidade (MHVG), adaptabilidade (PRVG), e estabilidade e adaptabilidade conjuntamente (MHPRVG) para o conjunto de locais (Tabela 5), observa-se que a população 0912520 foi superior às demais, seguida de BRS Planalto. Neste caso, os resultados coincidem com os valores de médias (Tabela 3), fato que nem sempre ocorre. CARBOnell et al. (2007) constataram variaçấo na coincidência, de modo que estimativas levando em conta a adaptabilidade e estabilidade propiciam um refinamento na recomendação de cultivares.

Diferente de AMMI e GGE Biplot que demonstraram certa relação positiva entre a cultivar BRS Planalto e Gama (DF) no sistema orgânico, o método REML/BLUP penalizou mais esta relação, o que parece de melhor explicaçãoo (Tabela 3). O método REML/BLUP diferenciouse das demais também quanto à indicação da população 0912520 como a de maior adaptabilidade e estabilidade, e não as populaçóes $0912532 \mathrm{e} \mathrm{BRS}$ Planalto. Este resultado parece mais aceitável, pois esta foi a populaçáo com a maior média conjunta de todos os locais e a mais produtiva em três dos cinco locais, enquanto 0912532 obteve a maior média em apenas um local e BRS Planalto em nenhum dos locais.

Entretanto, é preciso considerar que o método GGE Biplot capta apenas uma pequena porcentagem da variabilidade total, e a AMMI capta menos ainda, o que compromete a análise, pois se obtêm padrôes imprecisos, afirmando que há necessidade da utilização de modelos mistos (YANG et al., 2009). O método REML/ BLUP, sendo um modelo misto, fornece resultados que são interpretados diretamente como valores genotípicos, já penalizados ou capitalizados palas estimativas de estabilidade e adaptabilidade (CARbonell et al., 2007; VERARDI et al., 2009). 
Dentre os locais de cultivo orgânico, Gama (DF) proporcionou rendimentos maiores que PAD (DF). Já para os locais de cultivo convencional Sáo Gotardo (MG) foi superior aos demais.

\section{CONCLUSÃO}

As análises AMMI e GGE Biplot são bastante semelhantes na verificaçáo da adaptabilidade e estabilidade das populaçôes de cenoura, e GGE Biplot agrupa de maneira mais clara os ambientes mais favoráveis e desfavoráveis.

A análise REML/BLUP destaca-se das demais e apesar de não informar sobre agrupamento de locais mais semelhantes, apresenta os resultados em função de valores genotípicos levando em consideração os parâmetros de produtividade, adaptabilidade e estabilidade.

As populaçôes com melhor adaptabilidade e estabilidade são 0912532, BRS Planalto e 0912520.

\section{REFERÊNCIAS}

ASFAW, A.; ALEMAYEHU, F.; GURUM, F.; ATNAF, M. AMMI and GGE Biplot analysis for matching varieties onto soybean production environments in Ethiopia. Scientific Research and Essay, v.4, p.1322-1330, 2009.

BALESTRE, M.; SOUZA, J.C.; PINHO, R.G.V.; OLIVEIRA, R.L.; PAES, M.V. Yield stability and adaptability of maize hybrids based on GGE biplot analysis characteristics. Crop Breeding and Applied Biotechnology, v.9, p.219-228, 2009.

CAMPBELL, B.T.; JONES, M.A. Assessment of genotype $\mathrm{x}$ environment interactions for yield and fiber quality in cotton performance trials. Euphytica, v.144, p.69-78, 2005.

CARBONELL, S.A.M.; CHIORATO, A.F.; RESENDE, M.D.; DIAS, L.A.S; BERALDO, A.L.A.; PERINA, E.F. Estabilidade de cultivares e linhagens de feijoeiro em diferentes ambientes no Estado de São Paulo. Bragantia, v.66, p.193-201, 2007.

CEAGESP. Classificação de cenoura: programa de adesão voluntária. São Paulo: Programa Horti \& Fruti, 1999. 8p. (Fôlder).

CRUZ, C.D. Programa Genes: aplicativo computacional em genética e estatística. Viçosa: UFV, 1997. 442p.

CRUZ, C.D.; REGAZZI, A.J. Modelos biométricos aplicados ao melhoramento genético. Viçosa: UFV, 2001. 390p.

DUARTE, J.B.; ZIMMERMAN, M.J.O. Adaptabilidade e estabilidade de rendimento de genótipos de feijão comum. Pesquisa Agropecuária Brasileira, v.29, p.25-32, 1994.

DUARTE, J.B.; VENCOVSKY, R. Interação genótipos x ambientes: uma introdução à análise AMMI. Ribeirão Preto: Sociedade Brasileira de Genética, 1999. 60p. (Série Monografias, 9)
GAUCH, H.G. Statistical analysis of yield trials by AMMI and GGE. Crop Science, v.46, p.1488-1500, 2006.

GAUCH, H.G.; PIEPHO, H.P.; ANNICCHIARICO, P. Statistical Analysis of Yield Trials by AMMI and GGE: Further Considerations. Crop Science, v.48, p.866-889, 2008.

MOHAMMADI, R.; HAGHPARAST, R.; AGHAEE, M.; ROSTAEE, M.; POURDAD, S.S. Biplot Analysis of MultiEnvironment Trials for Identification of Winter Wheat Megaenvironments in Iran. World Journal of Agricultural Sciences, v.3, p.475-480, 2007.

NAMORATO, H.; MIRANDA, G.V.; SOUZA, L.V.; OLIVEIRA, L.R.; DELIMA, R.O.; MANTOVANI, E.E. Comparing biplot multivariate analyses with Eberhart and Russel method for genotype $\mathrm{x}$ environment interaction. Crop Breeding and Applied Biotechnology, v.9, p.299-307, 2009.

OLIVEIRA, A.B.; DUARTE, J.B; PINHEIRO, J.B. Emprego da análise AMMI na avaliação da estabilidade produtiva em soja. Pesquisa Agropecuária Brasileira, v.38, p.357-364, 2003.

OLIVEIRA, C.D.; BRAZ, L.T.; BANZATTO, D.A. Adaptabilidade e estabilidade genotípica de genótipos de cenoura. Horticultura Brasileira, v.23, p.743-748, 2005.

OLIVEIRA, C.D.; BRAZ, L.T.; BANZATTO, D.A. Adaptabilidade e estabilidade fenotípica de cultivares de cenoura. Horticultura Brasileira, v.26, p.88-92, 2008.

OSMANZAI, M.; SHARMA, R.C. High yielding stable wheat genotypes for the diverse environments in Afghanistan. International Journal of Agricultural Research, v.3, p.340-348, 2008.

RESENDE, M.D.V. Genética biométrica e estatística no melhoramento de plantas perenes. Brasília: Embrapa Informação Tecnológica, 2002. 975p.

SAS INSTITUTE (Cary, NC). SAS/STAT. User's Guide. GLMVARCOMP: version 6.4.ed. v.2, Cary, 1989. 846p.

SILVA, G.O.; VIEIRA, J.V. Componentes genéticos e fenotípicos para caracteres de importância agronômica em população de cenoura sob seleção recorrente. Horticultura Brasileira, v.26, p.481485, 2008.

SILVA, G.O.; VIEIRA, J.V.; VILELA, M.S. Seleção de caracteres de cenoura cultivada em dois sistemas de produçáo agroecológicos no Distrito Federal. Revista Ceres, v.56, p.595-601, 2009.

SOUZA, R.B.; ALCÂNTARA, F.A. Adubação no sistema orgânico de produção de hortaliças. Brasília (DF): Embrapa Hortaliças, 2008. (Circular técnica 65 - Publicação eletrônica)

VERARDI, C.K.; RESENDE, M.D.V.; COSTA, R.B.; GONÇALVES, P.S. Adaptabilidade e estabilidade da produção de borracha e seleçấo em progênies de seringueira. Pesquisa Agropecuária Brasileira, v.44, p.1277-1282, 2009.

VIEIRA, J.V.; SILVA, G.O. Tamanho mínimo de parcela para avaliação de caracteres de raiz em cenoura. Bragantia, v.67, p.817825, 2008. 
VIEIRA, J.V.; SILVA, G.O.; BOITEUX, L.S.; SIMON, P. Divergência genética entre acessos de cenoura pertencentes a grupos varietais distintos utilizando caracteres morfológicos. Horticultura Brasileira, v.27, p.468-472, 2009.

YAN, W.; HUNT, L.A.; SHENG, Q.L.; SZLAVNICS, Z. Cultivar evaluation and mega-environment investigation based on the GGE Biplot. Crop Science, v.40, p.597-605, 2000.

YAN, W.; KANG, M.S. GGE Biplot analysis: a graphical tool for breeders, geneticists, and agronomists. 1.ed. Boca Raton: CRC Press LLC, 2003. 288p.
YAN, W.; KANG, M.S.; MA, B.; WOODS, S.; CORNELIUS, P.L. GGE Biplots vs. AMMI analysis of genotype-by-environment data. Crop Science, v.47, p.643-655, 2007.

YANG, R.C.; CROSSA, J.; CORNELIUS, P.L.; BURGUEÑO, $\mathrm{J}$. Biplot analysis of genotype $\mathrm{x}$ environment interaction: proceed with caution. Crop Science, v.49, p.1564-1576, 2009.

ZOBEL, R. W.; WRIGHT, M. J.; GAUCH, H. G. Statistical analysis of a yield trial. Agronomy Journal, v.80, p.388-393, 1988. 